\title{
PENGARUH REKAM MEDIS ELEKTRONIK TERHADAP PENINGKATAN EFEKTIVITAS PELAYANAN RAWAT JALAN DI RUMAH SAKIT X
}

\author{
Tania Latipah ${ }^{1 *}$, Siti Solihah ${ }^{2}$, Sali Setiatin ${ }^{3}$ \\ Politeknik Piksi Ganesha ${ }^{1,2,3}$ \\ tlatipah@piksi.ac.id ${ }^{1 *}$, ssolihah@piksi.ac.id ${ }^{2}$, salisetiatin@gmail.com ${ }^{3}$
}

Received: 18-07-2021

Revised : 20-10-2021

Accepted: 24-10-2021

\begin{abstract}
Abstrak
Latar Belakang: Penggunaan Rekam Medis Elektronik (RME) di banyak pelayanan kesehatan diharapkan dapat menggantikan Rekam Medis Manual karena Rekam Medis Elektronik dianggap lebih efektif dan efisien dalam penggunaannya, banyak rumah sakit yang sudah mulai menggantikan Rekam Medis Manual (RMM) dengan Rekam Medis Elektronik (RME) termasuk Rumah Sakit X.
\end{abstract}

Tujuan: Penelitian ini bertujuan untuk mengetahui seberapa pengaruh penerapan Rekam Medis Elektronik (RME) terhadap peningkatan efektivitas khususnya pada pelayanan Rawat Jalan Rumah Sakit X.

Metode: Penelitian ini dilakukan pada tanggal 5-8 Juli 2021. Dengan menggunakan metode penelitian kuantitatif pendekatan deskriptif dengan desain penelitian korelasional. Penelitian dilakukan dengan menyebarkan kuesioner pada 30 Perekam Medis dan Informasi Kesehatan yang mengisi posisi tenaga kesehatan Rekam Medis Rumah Sakit X.

Hasil: Hasil penelitian menunjukan persentase dari aspek 4 Aspek efektivitas yang diteliti suatu program dalam hal ini RME dapat dikatakan efektif apabila program tersebut memenuhi Aspek Tugas dan Fungsi, Aspek Rencana atau Program, Aspek Ketentuan dan Peraturan, dan Aspek Tujuan atau Kondisi Ideal pada pelayanan Rawat Jalan saat diberlakukannya Rekam Medis Elektronik di Rumah Sakit X. Kesimpulan: Penelitian ini dapat disimpulkan bahwa tenaga kesehatan Rawat Jalan Rumah Sakit X setuju bahwa penerapan RME efektif pada 3 aspek yaitu; tugas atau fungsi rawat jalan, rencana atau program rawat jalan, ketentuan dan peraturan rawat jalan, adapula tenaga kesehatan Rawat Jalan Rumah Sakit X sangat setuju bahwa penerapan RME efektif pada aspek tujuan atau kondisi ideal Rawat Jalan Rumah Sakit X.

Kata kunci: rekam medis; rekam medis elektronik; efektivitas; rawat jalan.

\section{Abstract}


Background: The use of Electronic Medical Records (RME) in many health services is expected to replace Manual Medical Records because Electronic Medical Records are considered more effective and efficient in their use, many hospitals have begun to replace Manual Medical Records (RMM) with Electronic Medical Records (Electronic Medical Records). RME) including Hospital X.

Objective: This study aims to determine how much influence the application of Electronic Medical Records (RME) has on increasing effectiveness, especially in the Outpatient services of Hospital X.

Methods: This study was conducted on $5-8$ July 2021. By using descriptive quantitative research method with a correlational research design. The study was conducted by distributing questionnaires to 30 Medical Recorders and Health Information who fills the position of health workers in Hospital Medical Record X.

Results: The results of the study show the percentage of aspects of the 4 aspects of effectiveness studied by a program in this case RME can be said to be effective if the program meets the Aspects of Tasks and Functions, Aspects of Plans or Programs, Aspects of Provisions and Regulations, and Aspects of Goals or Ideal Conditions for Outpatient services when Electronic Medical Records are enacted in hospitals $X$. Conclusion: This research can be concluded that the outpatient health workers of Hospital $X$ agree that the application of RME is effective in 3 aspects, namely; outpatient duties or functions, outpatient plans or programs, outpatient rules and regulations, and the outpatient health workers of Hospital $X$ strongly agree that the application of $R M E$ is effective in the aspect of the goals or ideal conditions of Outpatient Hospital X.

Keywords: medical record; electronic medical records; effectiveness; outpatient.

*Correspondent Author : Tania Latipah Email : tlatipah@piksi.ac.id

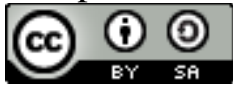

\section{PENDAHULUAN}

Rekam Medis dalam dunia Kesehatan sangat penting bagi sistem pelayanan Rumah Sakit karena berisikan catatan dan dokumen tentang identitas pasien, pemeriksaan, pengobatan, tindakan dan pelayanan lain yang telah diberikan kepada pasien. Salah satu penggunaan Teknologi Informasi (TI) di bidang kesehatan yang menjadi trend dalam pelayanan kesehatan secara global adalah Rekam Medis Elektronik (Susanto, 2012). Di Indonesia, dikenal dengan Rekam Medis Elektronik (RME). RME banyak digunakan di berbagai Rumah Sakit sebagai pengganti atau pelengkap Rekam Medis kesehatan manual 
berbentuk kertas (Khasanah, 2020). Penerapan RME di Rumah Sakit X sudah mulai sejak tahun 2004 dengan menggunakan metode Sistem Informasi Manajemen rumah sakit (SIMRS), dengan adanya SIMRS ini diharapkan dapat memudahkan para tenaga rekam medis untuk melayani dan mengolah data pasien khususnya pada pelayanan pendaftaran rawat jalan, adapula tugas dari pelayanan Rawat Jalan di Rumah Sakit X diantaranya : registrasi pasien, menginput data pasien pada SIMRS, membuat surat rujukan, indeksing dan assembling (Saputra, 2014).

Rekam Medis sendiri dalam penjelasan pasal 46 ayat (1) UU No. 29 Tahun 2004 Dalam kaitannya dengan praktik kedokteran, yang dimaksud dengan rekam medis adalah berkas yang berisi catatan dan dokumen yang berkaitan dengan identitas pasien, pemeriksaan, pengobatan, tindakan, dan pelayanan selain pasien (Indonesia, 2004). Pada PERMENKES No:269/MENKES/PER/III/2008 yang dimaksud dengan rekam medis adalah berkas yang berisi catatan dan dokumen yang memuat identitas pasien, hasil pemeriksaan, pengobatan yang telah diberikan, serta baik seperti prosedur dan layanan pakaian diberikan kepada pasien (Permenkes, 2008).

Menurut (Pribadi et al., 2018), Rekam Medis Elektronik (Computer-Based Medical Record) adalah tempat penyimpanan elektronik informasi tentang status kesehatan dan pelayanan kesehatan yang diperoleh pasien sepanjang hidupnya, disimpan sedemikian rupa sehingga dapat melayani berbagai rekam medis yang sah. pengguna. Rekam kesehatan elektronik juga harus mencakup data pribadi, demografi, sosial, klinis dan berbagai kejadian klinis selama proses pelayanan dari berbagai sumber data (multimedia) dan berfungsi secara aktif memberikan dukungan untuk pengambilan keputusan medis. Penggunaan rekam kesehatan elektronik menghasilkan sistem yang secara khusus memfasilitasi berbagai kemudahan bagi pengguna, seperti proses kelengkapan data, alert alert, sistem pendukung keputusan klinis dan data linking dengan pengetahuan medis dan alat lainnya (Darwito et al., 2016). Di Indonesia, rekam medis berbasis komputer ini biasa disebut Electronic Medical Record (EMR). Electronic Medical Record (EMR) adalah kegiatan komputerisasi isi rekam medis kesehatan dan proses-proses yang terkait dengannya (Dwijosusilo \& Sarni, 2018).

Rekam Medis adalah "kumpulan fakta tentang kehidupan seorang pasien dan riwayat penyakitnya, termasuk penyakitnya, perawatan saat ini dan masa lalu, yang ditulis oleh praktisi kesehatan dalam upayanya memberikan pelayanan kesehatan kepada pasien (Yulianthi, 2012). Electronic Medical Record (EMR) bukanlah suatu sistem informasi yang dapat dibeli dan dipasang seperti paket pengolah kata atau sistem informasi pembayaran dan laboratorium yang dapat langsung dihubungkan dengan sistem informasi dan alat lain yang sesuai di lingkungan tertentu (Rosa \& Kep, 2019). Menurut (Erlirianto, 2015), Electronic Medical Record (EMR) adalah suatu sistem informasi yang memiliki kerangka kerja yang lebih luas dan memenuhi seperangkat fungsi, menurut Amatayakul Magret $\mathrm{K}$ dalam bukunya Electronic Health Records: A Practical, Guide for Professionals and Organizations, Electronic Medical Record $(E M R)$ harus memenuhi kriteria sebagai berikut : a. Mengintegrasikan data dari berbagai sumber (Integrated Data From Multiple Sources). b. Mengumpulkan data di titik pelayanan (Capture Data At The Point Of Care). c. Mendukung penyedia layanan dalam pengambilan keputusan (Support Caregiver Decision Making) (Amatayakul, 2007).

Pelayanan Rawat Jalan adalah pelayanan kesehatan non spesifik yang dilakukan di fasilitas kesehatan yang berobat hanya pada jam kerja dan pasien tidak menginap di rumah sakit (Sondari, 2015). Menurut (Mayasari, 2018) pelayanan rawat jalan adalah pelayanan yang diberikan kepada pasien rawat jalan dan pelayanan tidak lebih dari 24 jam, termasuk semua prosedur diagnostik dan terapeutik. Kedepannya, pelayanan rawat jalan akan menjadi bagian terbesar dari pelayanan kesehatan di Puskesmas. Pesatnya pertumbuhan pelayanan rawat jalan ditentukan oleh tiga faktor, yaitu: 1) Pengurangan biaya untuk mengendalikan kenaikan harga 
pelayanan kesehatan dibandingkan rawat inap, 2) Peningkatan kapabilitas dan sistem reimbursement untuk prosedur rawat jalan, 3) Pengembangan teknologi tinggi yang berkelanjutan untuk prosedur rawat jalan. pelayanan rawat jalan akan mendorong pertumbuhan pelayanan rawat jalan. Pelayanan rawat jalan sering diibaratkan sebagai pintu gerbang pelayanan kesehatan yang akan mempengaruhi keputusan pasien untuk tetap atau tidak menggunakan pelayanan tersebut. Kualitas layanan ditentukan oleh kebutuhan atau harapan pengguna yang telah terpenuhi dan diterima tepat waktu. Jika pelayanan yang diharapkan sesuai dengan pelayanan yang diterima maka dianggap memuaskan dan mereka akan kembali memanfaatkan fasilitas pelayanan kesehatan (Napirah et al., 2016).

Adapula Efektivitas itu sendiri menurut (Rosmini, 2021), efektivitas adalah hubungan antara produk dengan tujuan atau bisa juga dikatakan sebagai ukuran sejauh mana tingkat produk, kebijakan dan prosedur organisasi. Efisiensi juga berkaitan dengan tingkat keberhasilan suatu operasi di sektor publik, sehingga suatu kegiatan dikatakan efektif jika kegiatan tersebut mempunyai pengaruh yang signifikan terhadap kemampuan memberikan pelayanan publik yang merupakan tujuan yang telah ditentukan.

Menurut (Yulitiawati \& Rusmidarti, 2021), efektivitas adalah ukuran keberhasilan atau kegagalan dalam mencapai tujuan suatu organisasi dalam mencapai tujuannya. Jika suatu organisasi mencapai tujuannya, maka organisasi tersebut telah beroperasi secara efektif. Indikator efektivitas menggambarkan jangkauan efek dan dampak (outcomes) dari keluaran program dalam mencapai tujuan program. Semakin besar kontribusi produk yang dihasilkan terhadap pencapaian tujuan atau sasaran yang telah ditentukan, maka akan semakin efisien proses kerja suatu unit organisasi. Pada penelitian yang dilakukan oleh (Farid et al, 2021) meneliti tentang efektivitas penggunaan Rekam Medis Elektronik terhadap pelayanan pasien rawat jalan yang efektif dan sangat membantu dalam proses pemberian pelayanan yang diberikan kepada pasien. Namun, penelitian tersebut tidak menjelaskan pengaruh penggunaan Rekam Medis Elektronik sehingga penulis meneliti seberapa besar pengaruh penggunaan Rekam Medis Elektronik pada peningkatan efektivitas pelayanan Rawat Jalan.

Aspek efektivitas berdasarkan pendapat (Azizah, 2018), efektivitas dapat dijelaskan bahwa efektivitas suatu program dapat dilihat dari aspek-aspek berikut: (1) Aspek tugas atau fungsi, dapat dikatakan efektif apabila lembaga tersebut menjalankan tugas atau fungsinya, demikian pula dengan penerapan program RME akan efektif apabila tugas dan fungsi dari rawat jalan dapat dilaksanakan secara memadai; (2) Aspek rencana atau program, yang dimaksud dengan rencana atau program, jika semua rencana dapat dilaksanakan, maka rencana atau program tersebut dikatakan efektif, demikian pula dengan penerapan program RME dapat dikatakan efektif jika jika semua rencana dan program di rawat jalan dapat dilaksanakan; (3) Aspek ketentuan dan peraturan, efektivitas suatu program juga dapat dilihat pada berjalannya peraturan, jika peraturan tersebut dilaksanakan dengan baik, berarti penerapan RME tersebut telah efektif berlaku; dan (4) Aspek tujuan atau kondisi ideal, suatu program kegiatan dapat dikatakan efektif dilihat dari hasil jika tujuan atau kondisi ideal program tersebut dapat dicapai, dalam hal ini penerapan RME dapat dikatakan efektif jika tujuan atau kondisi ideal penerapan RME di rawat jalan dapat dicapai.

Penelitian ini bertujuan untuk mengetahui pengaruh dari penerapan Rekam Medis Elektronik Terhadap Peningkatan Efektivitas Pelayanan Rawat Jalan di Rumah Sakit X, hasil dari penelitian ini diharapkan dapat menjadi bahan pertimbangan untuk evaluasi penerapan sistem Rekam Medis Elektronik khusunya di Rumah Sakit X agar sesuai dengan tujuan penerapan RME itu sendiri, penelitian ini diharapkan dapat bermanfaat khususnya untuk rumah sakit $\mathrm{x}$, dan dapat menjadi rujukan untuk rumah sakit di Indonesia yang juga melakukan penerapan RME khususnya di bagian rawat jalan. 


\section{METODE PENELITIAN}

Penelitian ini menggunakan metode penelitian kuantitatif pendekatan deskriptif, adapula penjelasan penelitian kuantitatif menurut (Sugiyono, 2013), metode penelitian kuantitatif dapat diartikan sebagai metode penelitian yang berlandaskan pada filsafat positivisme, digunakan untuk meneliti pada populasi atau sampel tertentu, teknik pengambilan sampel pada umumnya dilakukan secara random, pengumpulan data menggunakan instrumen penelitian, analisis data bersifat kuantitatif atau statistik dengan tujuan untuk menguji hipotesis yang telah ditetapkan. Penelitian ini menggunakan pendekatan deskriptif dengan tujuan untuk mendeskripsikan objek penelitian atupun hasil penelitian. Adapun pengertian deskriptif menurut (Sugiyono, 2014) adalah metode yang berfungsi untuk mendeskripsikan atau memberi gambaran terhadap objek yang diteliti melalui data atau sampel yang telah terkumpul sebagimana adanya, tanpa melakukun analisis dan membuat kesimpulan yang berlaku umum.

Penelitian ini bertujuan untuk mengetahui pengaruh penerapan RME pada peningkatan efektivitas pelayanan Rawat Jalan Rumah Sakit X. Departemen yang diteliti adalah Departemen Rekam Medis bagian pendaftaran Rawat Jalan Rumah Sakit X. Waktu penelitian ini dilakukan pada 5 - 8 Juli 2021.

Populasi pada penelitian ini adalah petugas Rekam Medis Rumah Sakit X, sampel penelitian merupakan seluruh populasi yaitu 30 Perekam Medis dan Informasi Kesehatan (PMIK) Rumah Sakit X. Adapula pengertian populasi menurut (Setiana, 2020) mengemukakan populasi adalah wilayah generalisasi yang terdiri atas: objek atau subjek yang mempunyai kualitasdan karakteristik tertentu yang ditetapkan oleh peneliti untuk dipelajari dan kemudian dapat di tarik kesimpulan.

Instrumen pada penelitian ini adalah kuesioner terstruktur, adapula menurut (Sari et al., 2016) menjelaskan bahwa kuesioner adalah sejumlah pertanyaan tertulis yang digunakan untuk memperoleh informasi dari responden dalam arti laporan pribadinya, atau hal yang diketahui oleh responden, untuk memperoleh informasi mengenai efektivitas penerapan RME terhadap peningkatan efektivitas pelayanan Rawat Jalan Rumah Sakit X, peneliti memberikan kuesioner berisi pernyataan yang berdasarkan dari aspek efektivitas menurut yaitu aspek tugas dan fungsi,aspek rencana atau program, aspek ketentuan dan peraturan, dan aspek tujuan atau kondisi ideal (Muasaroh, 2010), serta variabel terkait yaitu penerapan RME terhadap peningkatan efektivitas pelayanan Rawat Jalan Rumah Sakit X. Hasil pengumpulan data diolah menggunakan perangkat lunak statistik SPSS 16.

\section{HASIL DAN PEMBAHASAN}

\section{A. Hasil Penelitian}

\section{Uji Validitas Kuesioner}

Uji Validitas dilakukan dengan memberikan kuesioner pada 30 Perekam Medis dan Informasi Kesehatan, metode pengujian validitas pada penelitian ini menggunakan metode corrected item-total correlation, butir pernyataan akan dikatakan valid apabila $\mathrm{r}$ hitung lebih besar dari jumlah $\mathrm{r}$ table, dengan uji 2- sisi, dengan tingkat signifikasi yang digunakan adalah 0,05 . 
Gambar1. Hasil Uji Validitas Kuesioner

\begin{tabular}{ccccc}
\hline No & Butir Soal & R hitung & r table & Validitas \\
\hline 1 & $\mathrm{X} 1$ & 0,542 & 0,3 & Valid \\
\hline 2 & $\mathrm{X} 2$ & 0,764 & 0,3 & Valid \\
\hline 3 & $\mathrm{X} 3$ & 0,801 & 0,3 & Valid \\
\hline 4 & $\mathrm{X} 4$ & 0,689 & 0,3 & Valid \\
\hline 5 & $\mathrm{X} 5$ & 0,655 & 0,3 & Valid \\
\hline 6 & $\mathrm{X} 6$ & 0,791 & 0,3 & Valid \\
\hline 7 & $\mathrm{X} 7$ & 0,686 & 0,3 & Valid \\
\hline 8 & $\mathrm{X} 8$ & 0,415 & 0,3 & Valid \\
\hline 9 & $\mathrm{X} 9$ & 0,814 & 0,3 & Valid \\
\hline 10 & $\mathrm{X} 10$ & 0,813 & 0,3 & Valid \\
\hline 11 & $\mathrm{X} 11$ & 0,813 & 0,3 & Valid \\
\hline 12 & $\mathrm{X} 12$ & 0,453 & 0,3 & Valid \\
\hline 13 & $\mathrm{X} 13$ & 0,659 & 0,3 & Valid \\
\hline
\end{tabular}

Berdasarkan hasil uji validitas pada tabel 1 di atas, yang dilakukan pada 16 butir kuesioner, didapatkan hasil item valid sejumlah 13 item dengan nilai di atas 0,3. Angka yang diperoleh harus dibandingkan dengan standar nilai korelasi validitas, menurut Sugiyono (2017:125) nilai standar dari validitas adalah sebesar 0,361. Jika angka korelasi yang diperoleh lebih besar daripada nilai standar maka pertanyaan tersebut valid (Signifikan).

\section{Uji Reliabilitas Kuesioner}

Uji reliabilitas menggunakan metode Cronbach's alpha dimana pernyataan dapat dinyatakan reliabel apabila hasil Cronbach's alpha lebih dari 0,7

Gambar 2. Hasil Uji Reliabilitas Kuesioner

\begin{tabular}{cll}
\hline No & Cronbach's Alpha & N of Items \\
\hline 1 & 0,892 & 16 \\
\hline
\end{tabular}

Berdasarkan hasil uji reliabilitas kuesioner pada tabel 2 di atas, bahwa kuesioner mendapatkan hasil 0,892 atau lebih besar dari 0,7 sehingga kuesioner dapat dinyatakan reliabel, hal ini sesuai dengan pendapat Sugiyono (2017:130) yang menyatakan bahwa uji reliabilitas adalah sejauh mana hasil pengukuran dengan menggunakan objek yang sama, akan menghasilkan data yang sama. Uji reliabilitas dilakukan secara bersama-sama terhadap seluruh pernyataan.

Apabila korelasi 0,7 atau lebih maka dikatakan item tersebut memberikan tingkat reliabel yang cukup tinggi, namun sebaliknya apabila nilai korelasi dibawah 0,7 maka dikatakan item tersebut kurang reliabel.

\section{Karakteristik Perekam Medis dan Informasi Kesehatan (PMIK)}

Kuesioner disebar pada 30 Perekam Medis dan Informasi Kesehatan (PMIK) dengan karakteristik sebagian besar perempuan sejumlah (55\%), dengan profesi sebagai tenaga kesehatan Rekam Medis Rumah Sakit X (80\%), berusia 20-30 tahun (85\%), lama bekerja 1-5 tahun $(75 \%)$. 
Tabel 3. Jenis Kelamin Perekam Medis dan Informasi Kesehatan (PMIK)

\begin{tabular}{cll}
\hline No & Jenis Kelamin & Jumlah (orang) \\
\hline 1 & Perempuan & 16 \\
\hline 2 & Laki - Laki & 14 \\
\hline
\end{tabular}

Sumber: Data primer dan Data sekunder

Pada tabel 3 di atas, bahwa hasil sebaran kuesioner yang diberikan pada perekam medis yang bekerja di Rumah Sakit X, kuesioner diisi oleh perekam medis dengan jenis kelamin perempuan yang berjumlah 16 orang, dan Laki-laki dengan jumlah 14 orang.

Tabel 4. Profesi Perekam Medis dan Informasi Kesehatan (PMIK)

\begin{tabular}{cll}
\hline No & Profesi & Jumlah (orang) \\
\hline 1 & Tenaga Kesehatan Rekam Medis & 24 \\
\hline 2 & Tenaga Kesehatan Non Rekam Medis & 6
\end{tabular}

Sumber: Data primer dan Data sekunder

Pada tabel 4 di atas, dapat dilihat bahwa perekam medis yang bekerja di Rumah Sakit $\mathrm{X}$ berprofesi sebagai Tenaga Kesehatan Rekam Medis berjumlah 24 orang dan Tenaga Kesehatan Non Rekam Medis berjumlah 6 orang.

Tabel 5. Usia Perekam Medis dan Informasi Kesehatan (PMIK)

\begin{tabular}{cll}
\hline No & Usia & Jumlah (orang) \\
\hline 1 & $20-30$ Tahun & 25 \\
\hline 2 & $31-40$ Tahun & 5 \\
\hline
\end{tabular}

Sumber: Data primer dan Data sekunder

Pada tabel 5 di atas, bahwa didapatkan data bahwa dari sampel yang terambil sebanyak 30 Perekam Medis dan Informasi Kesehatan. Terdapat 2 pengelompokan usia dan yang didominasi pada rentang umur 20-30 Tahun sebanyak 25 orang, serta usia 31-40 Tahun sebanyak 5 orang.

Tabel 6. Lama Bekerja Perekam Medis dan Informasi Kesehatan (PMIK)

\begin{tabular}{cll}
\hline No & Durasi Kerja & Jumlah (orang) \\
\hline 1 & $1-5$ Tahun & 23 \\
\hline 2 & $6-10$ Tahun & 7 \\
\hline
\end{tabular}

Sumber: Data primer dan Data sekunder

Pada tabel 6 hasil sebaran kuesioner yang diberikan pada 30 Perekam Medis dan Informasi Kesehatan (PMIK) kuesioner diisi oleh responden dengan lama bekerja 1-5 Tahun dengan jumlah sebanyak 23 orang dan yang lama bekerja selama 6-10 Tahun berjumlah 7 orang. 


\section{Hasil Sebaran Kuesioner}

Tabel 7. Hasil Sebaran Kuesioner Dengan Skala likert

\begin{tabular}{cll}
\hline No & Aspek & Kategori Index Interval \\
\hline 1 & Tugas Atau Fungsi & $76 \%$ (Setuju) \\
\hline 2 & Rencana Atau Program & $71 \%$ (Setuju) \\
\hline 3 & Ketentuan Dan Peraturan & $65 \%$ (Setuju) \\
\hline 4 & Tujuan Atau Kondisi Ideal & $81 \%$ (Sangat Setuju) \\
\hline
\end{tabular}

Sumber: Data primer dan Data sekunder

Berdasarkan tabel 7 di atas, bahwa hasil sebaran kuesioner dengan skala likert, dapat disimpulkan tenaga kesehatan Rawat Jalan Rumah Sakit X Setuju bahwa penerapan RME efektif pada aspek tugas atau fungsi berdasarkan dari kategori nilai index $76 \%$, tenaga kesehatan Rawat Jalan Rumah Sakit X setuju bahwa penerapan RME efektif pada aspek rencana atau program berdasarkan dari kategori nilai index 71\%, tenaga kesehatan Rawat Jalan Rumah Sakit X setuju bahwa penerapan RME efektif pada aspek ketentuan dan peraturan berdasarkan dari kategori nilai index 65\%, tenaga kesehatan Rawat Jalan Rumah Sakit X sangat setuju bahwa penerapan RME efektif pada aspek tujuan atau kondisi ideal berdasarkan dari kategori nilai index $81 \%$, maka dengan demikian dapat disimpulkan dari 4 aspek yang diteliti terkait efektivitas menurut (Muasaroh, 2010), bahwa tenaga kesehatan Rawat Jalan Rumah Sakit X setuju bahwa penerapan RME efektif pada 3 aspek yaitu; tugas atau fungsi rawat jalan, rencana atau program rawat jalan, ketentuan dan peraturan rawat jalan, adapula tenaga kesehatan Rawat Jalan Rumah Sakit X sangat setuju bahwa penerapan RME efektif pada aspek tujuan atau kondisi ideal Rawat Jalan Rumah Sakit X.

\section{B. Pembahasan}

Hasil dari pengambilan data dihitung dan disimpulkan menggunakan skala likert, adapula penggunaan skala likert untuk mengukur sikap, pendapat, dan persepsi seseorang atau sekelompok orang tentang fenomena sosial. Dalam penelitian, fenomena sosial ini telah ditetapkan secara spesifik oleh peneliti, yang selanjutnya disebut sebagai variabel penelitian. Dengan skala likert, maka variabel yang akan diukur dijabarkan menjadi indikator variabel. Kemudian indikator tersebut dijadikan sebagai titik tolak untuk menyusun item - item instrumen yang dapat berupa pernyataan atau pertanyaan ( $\underline{\text { Sugiyono, }}$ 2014).

Pendistribusian hasil pengambilan data kuesioner menggunakan rumus penentuan skala likert sebagai berikut:

\section{Rumus: T x Pn}

$\mathrm{T}=$ Total jumlah responden yang memilih

$\mathrm{Pn}=$ Angka skor likert

\section{Interpretasi Skor Perhitungan}

$\mathrm{Y}=$ skor tertinggi likert $\mathrm{x}$ jumlah responden

$\mathrm{X}=$ skor terendah likert $\mathrm{x}$ jumlah responden

Index $=$ Total Skor $/$ Y x 100

Hasil $=$ Total skor $/$ Y x $100=$ Hasil Interval\%

Tabel 8. Kategori Index Interval Skala Likert

No Index Kategori Index Interval




\begin{tabular}{lll}
\hline 1 & $0 \%-19,99 \%$ & Sangat Tidak Setuju \\
\hline 2 & $20 \%-39,99 \%$ & Tidak Setuju \\
\hline 3 & $40 \%-59,99 \%$ & Ragu - Ragu \\
\hline 4 & $60 \%-79,99 \%$ & Setuju \\
\hline 5 & $80 \%-100 \%$ & Sangat Setuju \\
\hline
\end{tabular}

\section{Aspek Tugas atau Fungsi}

Aspek tugas atau fungsi, yaitu lembaga dikatakan efektivitas jika melaksanakan tugas atau fungsinya (Muasaroh, 2010). Berdasarkan hasil sebaran kuesioner yang diberikan pada 30 responden didapatkan hasil bahwa, 5\% Perekam Medis dan Informasi Kesehatan sangat tidak setuju, 7\% Perekam Medis dan Informasi Kesehatan tidak setuju, 28\% Perekam Medis dan Informasi Kesehatan kurang setuju, 26\% Perekam Medis dan Informasi Kesehatan setuju, 34\% Perekam Medis dan Informasi Kesehatan sangat setuju bahwa penerapan Rekam Medis Elektronik efektif terhadap aspek tugas dan fungsi pada pelayanan Rawat Jalan Rumah Sakit X.

Berdasarkan hasil penghitungan skala likert yang dilakukan dapat disimpulkan bahwa tenaga kesehatan Rawat Jalan Rumah Sakit X setuju bahwa penerapan RME efektif pada aspek tugas atau fungsi berdasarkan dari kategori nilai index $76 \%$.

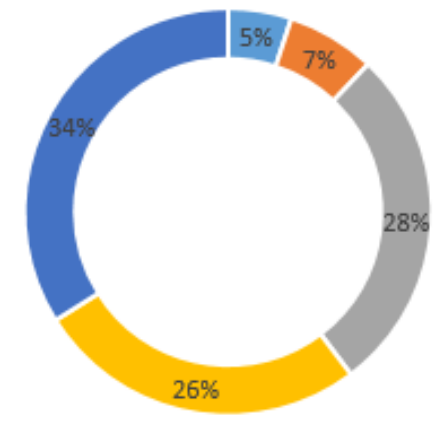

" sangat tidak setuju = tidak setuju = Kurang Setuju = Setuju = Sangat Setuju

Gambar 1. Diagram Persentase Jawaban Responden Aspek Tugas Atau Fungsi

\section{Aspek Rencana atau Program}

Jika seluruh rencana dapat dilaksanakan maka rencana atau program dikatakan efektif (Muasaroh, 2010). Berdasarkan hasil sebaran kuesioner yang diberikan pada 30 Perekam Medis dan Informasi Kesehatan didapatkan hasil bahwa, 3\% Perekam Medis dan Informasi Kesehatan sangat tidak setuju, 17\% Perekam Medis dan Informasi Kesehatan tidak setuju, 30\% Perekam Medis dan Informasi Kesehatan kurang setuju, 22\% Perekam Medis dan Informasi Kesehatan setuju, 28\% Perekam Medis dan Informasi Kesehatan sangat setuju bahwa penerapan Rekam Medis Elektronik efektif terhadap aspek rencana atau program pada pelayanan Rawat Jalan Rumah Sakit X.

Berdasarkan hasil penghitungan skala likert yang dilakukan dapat disimpulkan bahwa tenaga kesehatan Rawat Jalan Rumah Sakit X setuju bahwa penerapan RME efektif pada aspek rencana atau program berdasarkan dari kategori nilai index $71 \%$. 


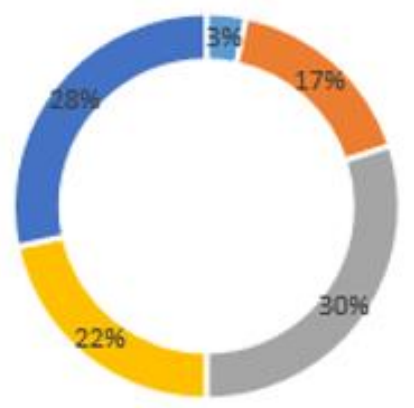

= sangat tidaksetuju = tidaksetuju =Kurang Setuju "Setuju " Sangat Setuju

Gambar 2. Diagram Persentase Jawaban Responden Aspek Rencana Atau Program

\section{Aspek Ketentuan dan Peraturan}

Aturan dilaksanakan dengan baik berarti ketentuan atau aturan telah berlaku secara efektif (Muasaroh, 2010). Berdasarkan hasil sebaran kuesioner yang diberikan pada 30 Perekam Medis dan Informasi Kesehatan didapatkan hasil bahwa, 11\% Perekam Medis dan Informasi Kesehatan sangat tidak setuju, 12\% Perekam Medis dan Informasi Kesehatan tidak setuju, 33\% Perekam Medis dan Informasi Kesehatan kurang setuju, 26\% Perekam Medis dan Informasi Kesehatan setuju, 18\% Perekam Medis dan Informasi Kesehatan sangat setuju bahwa penerapan Rekam Medis Elektronik efektif terhadap aspek ketentuan dan peraturan pada pelayanan Rawat Jalan Rumah Sakit X.

Berdasarkan hasil penghitungan skala likert yang dilakukan dapat disimpulkan bahwa tenaga kesehatan Rawat Jalan Rumah Sakit X setuju bahwa penerapan RME efektif pada aspek ketentuan dan peraturan berdasarkan dari kategori nilai index $65 \%$.

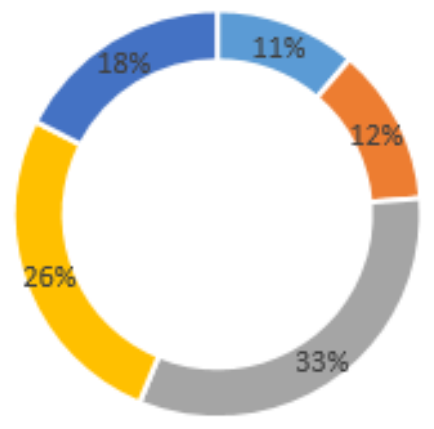

" sangat tidak setuju = tidak setuju = Kurang Setuju " Setuju " Sangat Setuju

Gambar 3. Diagram Persentase Jawaban Responden Aspek Ketentuan dan Peraturan

\section{Aspek Tujuan atau Kondisi Ideal}

Suatu program kegiatan dikatakan efektif dari sudut hasil jika tujuan atau kondisi ideal program tersebut dapat dicapai (Muasaroh, 2010). Berdasarkan hasil sebaran kuesioner yang didapatkan dari 30 Perekam Medis dan Informasi Kesehatan didapatkan hasil bahwa, 2\% Perekam Medis dan Informasi Kesehatan sangat tidak setuju, 5\% Perekam Medis dan Informasi Kesehatan tidak setuju, 20\% Perekam Medis dan Informasi Kesehatan agak setuju, 33\% Perekam Medis dan Informasi Kesehatan setuju, 40\% Perekam Medis dan Informasi Kesehatan sangat setuju bahwa penerapan 
Rekam Medis Elektronik efektif terhadap aspek tujuan atau kondisi ideal pada pelayanan Rawat Jalan Rumah Sakit X.

Berdasarkan hasil penghitungan skala likert yang dilakukan dapat disimpulkan bahwa tenaga kesehatan Rawat Jalan Rumah Sakit X sangat setuju bahwa penerapan RME efektif pada aspek tujuan atau kondisi ideal berdasarkan dari kategori nilai index $81 \%$.

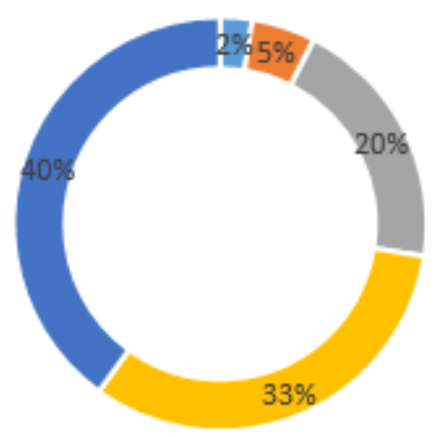

" sangat tidak setuju = tidak setuju | Kurang Setuju | Setuju | Sangat Setuju

Gambar 4. Diagram Persentase Jawaban Responden Aspek Tujuan Atau Kondisi Ideal

\section{KESIMPULAN}

Penggunaan Rekam Medis Elektronik di banyak pelayanan kesehatan diharapkan dapat menggantikan Rekam Medis Manual (RMM) karena Rekam Medis Elektronik dianggap lebih efektif dan efisien dalam penggunaannya, banyak Rumah Sakit yang sudah mulai menggantikan Rekam Medis Manual dengan Rekam Medis Elektronik termasuk Rumah Sakit X. Penelitian ini merupakan penelitian yang ditujukan untuk mengetahui seberapa besar pengaruh penggunaan Rekam Medis Elektronik pada peningkatan efektivitas pelayanan Rawat Jalan Rumah Sakit X.

Adapula hasil dari penelitian ini berupa penelitian deskriptif dengan hasil sebaran kuesioner yang dihitung menggunakan skala likert disimpulkan bahwa tenaga kesehatan Rawat Jalan Rumah Sakit X setuju bahwa penerapan RME efektif pada 3 aspek yaitu; tugas atau fungsi rawat jalan, rencana atau program rawat jalan, ketentuan dan peraturan rawat jalan, adapula tenaga kesehatan Rawat Jalan Rumah Sakit X sangat setuju bahwa penerapan RME efektif pada aspek tujuan atau kondisi ideal Rawat Jalan Rumah Sakit X. Dengan meneliti variabel efektivitas dari penerapan Rekam Medis Elektronik penelitian ini diharapkan dapat membantu proses evaluasi terhadap program Rekam Medis Elektronik yang telah dijalankan oleh banyak instansi pelayanan kesehatan khususnya Rumah Sakit X.

\section{BIBLIOGRAFI}

Amatayakul, M. (2007). Electronic health records: A practical guide for professionals and organizations. Amer Health Information Management.

Azizah, S. N. (2018). Efektivitas kinerja keuangan badan amil zakat nasional (baznas) pada program pentasharufan dana zakat di baznas kota yogyakarta. El-Jizya: Jurnal Ekonomi Islam, 6(1), 91-112.

Darwito, H. A., Yuliana, M., \& Azkiya, M. U. (2016). Implementasi Sistem Keamanan Sharing Electronic Health Record (EHR) Berbasis 3DES. SENTIA 2016, 8(2). 
Dwijosusilo, K., \& Sarni, S. (2018). Peranan Rekam Medis Elektronik Terhadap Sistim Informasi Manajemen Rumah Sakit di Rumah Sakit Umum Haji Surabaya.

Erlirianto, L. M. (2015). Implementasi Kerangka Kerja Evaluasi Human, Organization, And Technology-Fit (Hot-Fit) Pada Sistem Informasi Rekam Medis Elektronik (RME) Di Rumah Sakit Kristen Mojowarno, Jombang-The Implementation Of Human, Organization, And Technology-Fit (Hot-Fit) Eva. Institut Teknologi Sepuluh Nopember.

Farid, Z. M., Fernando, N. R., \& Sonia, D., \& Ganesha, P. P. (2021). Efektivitas penggunaan rekam medis elektronik terhadap pelayanan pasien rawat jalan di klinik darul arqam garut. 1(September), 1247-1254.

Indonesia, R. (2004). Undang-Undang Nomor 29 Tahun 2004 tentang Praktik Kedokteran. Jakarta: Republik Indonesia.

Khasanah, M. (2020). Tantangan Penerapan Rekam Medis Elektronik Untuk Instansi Kesehatan. Jurnal Sainstech, 7(2), 50-53.

Mayasari, F. (2018). Analisis hubungan waktu pelayanan dan faktor total quality service terhadap kepuasan pasien di poliklinik kebidanan dan kandungan RSIA Anugerah Medical Centre kota Metro tahun 2015. Jurnal Administrasi Rumah Sakit Indonesia, 2(3).

Muasaroh, S. (2010). Pengaruh Pemanfaatan Koleksi Perpustakaan Terhadap Peningkatan Minat Baca Siswa SMA Negeri 1 Kendal. Perpustakaan SMAN 1 Kendal.

Napirah, M. R., Rahman, A., \& Tony, A. (2016). Faktor-faktor yang berhubungan dengan pemanfaatan pelayanan kesehatan di wilayah kerja Puskesmas Tambarana Kecamatan Poso Pesisir Utara Kabupaten Poso. Jurnal Pengembangan Kota, 4(1), 29-39.

Permenkes, R. I. (2008). Peraturan Menteri Kesehatan Republik Indonesia No. 269/MenKes/Per/III/2008 tentang Rekam Medis. Jakarta: Kementerian Kesehatan RI.

Pribadi, Y., Dewi, S., \& Kusumanto, H. (2018). Analisis Kesiapan Penerapan Rekam Medis Elektronik di Kartini Hospital Jakarta. Jurnal Bidang Ilmu Kesehatan, 8(2), 19.

Rosa, D. R. E. M., \& Kep, M. (2019). Surveillance Infeksi Di Rumah Sakit Konsep dan Implementasi.

Rosmini, R. (2021). Analisis Efektivitas Pengelolaan Anggaran Pendapatan Dan Belanja Desa (Apbdes) Pada Desa Plampang Kecamatan Plampang Kabupaten Sumbawa. Universitas_Muhammadiyah_Mataram.

Saputra, E. (2014). Analisis penerimaan sistem informasi manajemen rumah sakit umum daerah Bangkinang menggunakan metode technology acceptance model (TAM). Jurnal Sains, Teknologi Dan Industri, 10(2), 229-235.

Sari, N. M. K., Suwena, K. R., \& Zukhri, A. (2016). Pengaruh Partisipasi Anggota, Pelayanan, dan Permodalan Terhadap Keberhasilan Usaha Koperasi Dharma Sesana Desa Lebih Kabupaten Gianyar. Jurnal Pendidikan Ekonomi Undiksha, 7(2).

Setiana, A. (2020). Pengaruh Penggunaan Model Cooperative Learning Tipe Picture And Picture Berbasis Web Terhadap Hasil Belajar Ekonomi Peserta Didik Kelas X Sma Negeri 1 Gunung Terang Tahun Pelajaran 2018/2019. https://ummetro. ac. id/.

Sondari, A. (2015). Analisis Kepuasan Pasien Rawat Jalan Peserta Jaminan Kesehatan Nasional (Jkn) Di Rumah Sakit Umum Daerah (Rsud) Kabupaten Brebes Tahun 2015. Universitas Negeri Semarang.

Sugiyono. (2013). Metode Penelitian Pendidikan Pendekatan Kuantitatif, Kualitatif, dan R\&D. In Bandung: Alfabeta.

Sugiyono. (2014). Metode Penelitian Kuantitatif Kualitatif Dan $R \& D$ (12th, Cetaka ed.). CV Alfabeta.

Pengaruh Rekam Medis Elektronik Terhadap Peningkatan Efektivitas Pelayanan Rawat Jalan di Rumah Sakit $X$ 
Susanto, G. (2012). Sistem Informasi Rekam Medis Pada Rumah Sakit Umum Daerah (RSUD) Pacitan Berbasis Web Base. Speed-Sentra Penelitian Engineering Dan Edukasi, 3(4).

Yulianthi, D. (2012). Pengaruh Karakteristik Individu Dan Psikologis Terhadap Kinerja Perawat Dalam Kelengkapan Rekam Medis Di Ruang Rawat Inap Rumah Sakit Stella Maris Makassar (Studi Kasus). Universitas Hasanuddin.

Yulitiawati, Y., \& Rusmidarti, R. (2021). Analisis Pengukuran Kinerja Organisasi Sektor Publik Dengan Mengunakan Pendekatan Value For Money Di Kabupaten OKU. JETAP, 1(2), 91-109.

(C) 2021 by the authors. Submitted for possible open access publication under the terms and conditions of the Creative Commons Attribution (CC BY SA) license (https://creativecommons.org/licenses/by-sa/4.0/). 